\title{
Beating 'Guangdong cancer': a review and update on nasopharyngeal cancer
}

\author{
CS Ho *
}

This article was published on 1 Sep 2017 at www.hkmj.org.

\section{A B S T R A C T}

Once endemic in southern China, nasopharyngeal cancer is becoming less prevalent in Hong Kong. This is probably due to a better understanding of the risk factors associated with the disease, its genomic landscape, advances in radiotherapy technology, and development of effective systemic agents. More specifically, the close relationship between EpsteinBarr virus and nasopharyngeal cancer opens up the possibility of using Epstein-Barr virus DNA as a biomarker for early detection and monitoring of the disease. On the other hand, the looming genomic data for nasopharyngeal cancer aid in the development of powerful biomarkers and promising targeted therapy. Clinical use of a combination of radiotherapy and chemotherapy continues to increase, while the development of immunotherapy, such as checkpoint inhibitors, offers hope in improving treatment outcome.

\section{Hong Kong Med J 2017;23:497-502 \\ DOI: $10.12809 / \mathrm{hkmj} 176834$}

CS Ho *, BPharm

Faculty of Medicine, The Chinese University of Hong Kong, Shatin, Hong Kong

* Corresponding author: jasonho@link.cuhk.edu.hk

\section{Introduction}

Nasopharyngeal cancer (NPC) was once considered endemic in the southern part of China. This type of cancer was so prevalent in Guangdong Province in southern China in the early 20th century that it was dubbed 'Guangdong cancer.1 Although the name is now less popular and the incidence of NPC has been decreasing since then (Fig), ${ }^{2,3}$ its occurrence in Hong Kong and Southeast Asia is still considerably higher than in other parts of the world: the age-standardised incidence rate was 7.9 per 100000 population in 2014 in Hong Kong, ${ }^{3}$ compared with less than 1.0 per 100000 population in North America and Europe. ${ }^{4}$ The global data from GLOBOCAN in 2012 showed that $38 \%$ of all new cases of NPC were registered in China. ${ }^{5}$

While Hong Kong is one of the regions that experience the most NPC, ${ }^{6}$ it has also become a centre for NPC research. Indeed, many important and landmark studies in NPC were performed in Hong Kong, where local experts have been responsible for developing practice guidelines with regard to the diagnosis, management, and follow-up of NPC. ${ }^{7,8}$ It is thus interesting to review the updated knowledge about the aetiology, risk factors, diagnosis, and treatment strategies of this 'Guangdong cancer'.

\section{Classification, aetiology, and risk factors}

\section{Classification and staging}

Nasopharyngeal cancer can be categorised according to its histopathology: keratinising, non-keratinising (which can be further subdivided into differentiated and undifferentiated forms), and basaloid squamous cell carcinoma; all of which are to replace the old numerical classification system. ${ }^{9}$ In endemic regions such as Hong Kong, non-keratinising carcinoma predominates, whereas the keratinising type is more common in other parts of the world. ${ }^{10}$

Nasopharyngeal cancer is staged according to the tumour, node, metastasis system. To assist with the prognosis and guide treatment decisions, NPC can be further stratified into five different stages (stages I, II, III, IVA, and IVB), as suggested by the latest American Joint Committee on Cancer (8th edition) cancer staging manual. ${ }^{11}$

\section{Viral factors}

While it is widely believed that NPC is caused by the interaction of several factors, Epstein-Barr virus (EBV) infection is undoubtedly the most studied aetiological factor for NPC. This virus-as a primary aetiological agent of NPC, specifically the endemic non-keratinising type-has been supported by a large body of evidence ${ }^{12}$; a review in 2012 suggested that EBV accounted for more than $85 \%$ of NPC cases globally. ${ }^{13}$ Based on in-situ hybridisation techniques ${ }^{10}$ and the fact that EBV infects more than $90 \%$ of the population, ${ }^{14}$ EBV reactivation is considered necessary in the pathogenesis of NPC; inhibition of EBV reactivation is currently being investigated as a possible approach to preventing NPC relapse. ${ }^{15}$ What triggers the reactivation, however, is less welldefined, although cigarette smoking is among the possible reactivating factors. ${ }^{16,17}$

On the other hand, human papillomavirus (HPV), a common aetiological agent causing cervical cancer, is associated with the non-endemic, keratinising type of NPC, although evidence is 


\section{對付「廣東癌」：鼻咽癌的回顧與更新 何卓生}

鼻咽癌於中國南部等地曾經令人聞之色變。隨著我們更瞭解鼻咽癌的 風險因素、基因圖譜, 以及更有效的治療方法, 近年發病率呈下降趨 勢。當中, 艾伯斯坦一巴爾病毒 (EBV) 與鼻咽癌的密切關係為EBV 脱氧核糖核酸的臨床應用打開了大門, 例如早期篩檢和病情監察。鼻 咽癌的基因數據則有助研究相關生物指標和標靶治療藥物的發展。治 療方面, 放射治療和化療的組合治療於臨床上的應用日趨常見, 而免 疫療法的面世則為治療帶來了新希望。

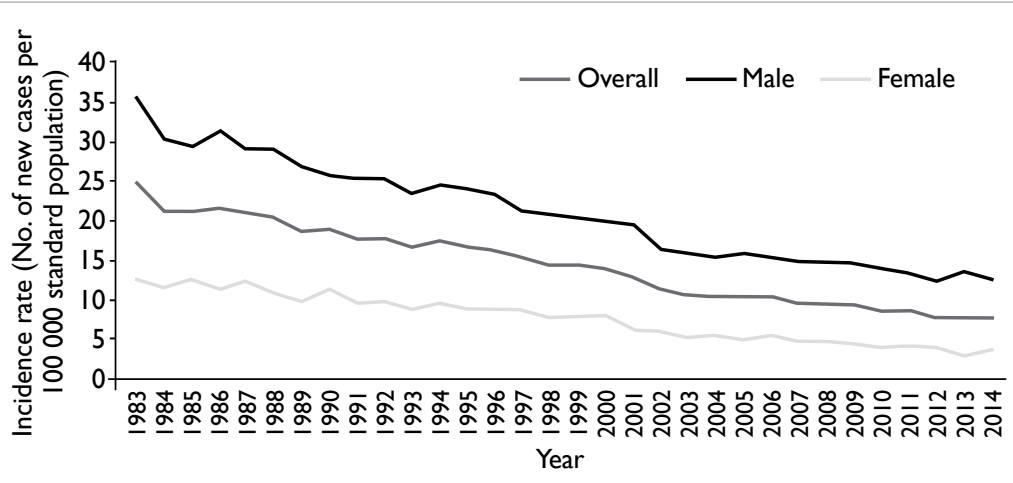

FIG. Age-standardised incidence rate of nasopharyngeal cancer by sex from 1983 to $2014^{2,3}$ subgroup of NPC patients. ${ }^{22}$ Although much in this field remains to be elucidated, it is expected that the genetic research will aid in the development of powerful biomarkers for the diagnosis, prognosis, and evaluation of the treatment for NPC. ${ }^{21}$

\section{Environmental factors}

An increased risk of NPC has been associated with a number of lifestyle factors, among which a history of salted fish consumption has the strongest association. Various studies have confirmed its association with $\mathrm{NPC},{ }^{, 3,24}$ and its relationship with the high prevalence of NPC in Hong Kong and neighbouring regions in the 20th century. ${ }^{6} \mathrm{~N}$-nitrosamine found in the preserved salted fish is believed to be the carcinogen concerned. ${ }^{25}$ Other factors such as the use of Chinese medicinal herbs and high consumption of fermented food were also suggested, but the associations were often inconsistent among studies. ${ }^{24}$

\section{Diagnosis}

Nasendoscopy for a biopsy sample is essential for a definitive diagnosis of NPC. Detecting and diagnosing NPC at an early stage is of paramount importance: the disease stage is significantly correlated with the outcome in NPC, and early diagnosis may improve outcomes..$^{12}$ Cell-free EBV DNA analysis was shown to have high sensitivity and specificity in detecting NPC, and has been further validated by various studies. ${ }^{26}$ A local study further showed that the analysis was useful in detecting early-stage NPC in asymptomatic individuals. ${ }^{27}$ An expanded phase II study involving over 20000 participants to evaluate its feasibility as a screening tool (NCT02063399) has just been completed, showing excellent sensitivity and specificity ( $97.1 \%$ and $98.6 \%$, respectively). ${ }^{28}$ Participants who were identified with NPC by this screening tool were detected significantly earlier and with better outcome when compared with those in a historical control. ${ }^{28}$

\section{Other roles of Epstein-Barr virus DNA}

With the substantial involvement of EBV in the pathogenesis of NPC, it is sensible to exploit EBV DNA as a biomarker in managing patients with NPC. One such application is the prediction of disease recurrence after treatment. Post-treatment EBV DNA level has been shown to be the most powerful predictor for disease recurrence and long-term survival in NPC patients of different ethnic origins, clinical stages, and treatment modalities. ${ }^{29-36}$ Recently Lee et $\mathrm{al}^{37}$ demonstrated that serial post-intensity modulated radiation therapy (IMRT) undetectable plasma EBV DNA was prognostic of all predefined survival end-points at 3 years in the modern IMRT era. Leung et $\mathrm{a}^{38}$ further showed that detectable plasma 
EBV DNA level at midcourse of radiotherapy (RT) or chemoradiotherapy (CRT) is adversely associated with worse overall survival (OS) and progressionfree survival (PFS). This suggests the possibility of shifting prognostication from a post-therapy timepoint to midcourse of therapy, and selecting highrisk patients for therapy intensification by measuring midcourse plasma EBV DNA level. ${ }^{38}$

Another notable application is the prediction of treatment outcome by measuring the clearance rate of plasma EBV DNA. Following the observation that EBV DNA was rapidly cleared from the circulation after surgical resection of NPC, ${ }^{39}$ subsequent studies demonstrated that patients with more rapid clearance of plasma EBV DNA responded better to chemotherapy or CRT compared with patients with a slower clearance ${ }^{40,41}$ A prospective trial evaluating the response to chemotherapy by measuring plasma EBV DNA half-life together with tumour metabolic response (via fluorodeoxyglucose positron emission tomographic scan) is currently underway.

\section{Treatment strategies}

\section{Radiotherapy}

Radiotherapy has long been regarded as the mainstay of NPC treatment, due to the radiosensitive nature of the tumour, and the anatomical position of NPC that limits a surgical approach. ${ }^{10}$ Of note, IMRT is currently the preferred approach, with its improved OS and decreased toxicity, ${ }^{42}$ advantages in preserving parotid function and reducing severe xerostomia, ${ }^{43}$ and improved quality of life compared with conventional two-dimensional (2D) RT. ${ }^{44}$ It is currently used as a monotherapy for the early stage of NPC.

Since the pre-IMRT era, re-irradiation has been shown to be effective in non-metastatic, recurrent NPC (rNPC) patients after primary $\mathrm{RT}^{45-47}$ With its introduction, IMRT has quickly emerged as the radiation modality of choice for $\mathrm{rNPC}$ as well, with or without the use of chemotherapy. Its efficacy has been established in various studies, with documented long-term OS rates ranging from $45 \%$ to $65 \% .{ }^{48-56}$ Yet, most of the patients in those studies were treated with conventional 2D-RT in the pre-IMRT era. In a recent study conducted by Kong et $\mathrm{al}^{56}{ }^{57}$ patients received salvage IMRT for rNPC after a definitive course of primary IMRT. While the median OS and PFS were 37.0 and 20.5 months, respectively, of particular note is the reirradiation toxicity. Of 34 patients, 18 died from treatment-induced severe adverse effects without evidence of disease progression during the study, including mucosal necrosis, temporal lobe necrosis, and cranial neuropathy, ${ }^{56}$ reflecting the limitations of salvage IMRT in the modern IMRT era. Other radiation modalities have been proposed, including particle therapy using proton and carbon ions, ${ }^{57}$ but long-term data are not yet available.

\section{Chemotherapy}

Chemotherapy is another important modality in managing NPC, and it is often combined with RT in the intermediate and advanced stages of NPC. The benefit of CRT was well-illustrated in a metaanalysis of seven trials, which showed significantly improved OS and 10-year PFS in the CRT group compared with the RT-alone group. ${ }^{58} \mathrm{~A}$ platinumbased regimen is often used as the chemotherapy of choice, in which cisplatin is most commonly used. ${ }^{10}$

While it is clear that chemotherapy is essential in the treatment of advanced NPC, its value as an add-on induction therapy (preceding CRT) and adjuvant therapy (following CRT) is less clear. Regarding induction therapy, a phase III trial recently showed that the addition of docetaxel, cisplatin, and fluorouracil prior to CRT was superior to CRT alone in terms of OS and PFS at 3 years, ${ }^{59}$ although another trial using cisplatin and fluorouracil as induction therapy failed to show significant differences in OS. ${ }^{60}$ The role of induction therapy requires further confirmation from other ongoing phase III trials.

Meanwhile, the use of adjuvant chemotherapy following CRT is debatable. A phase III trial with a median follow-up of 68.4 months failed to show significantly improved OS and PFS after adding cisplatin and fluorouracil as adjuvant therapy postCRT in locally advanced NPC, ${ }^{61}$ but another study suggested adjuvant chemotherapy might be reserved for high-risk patients defined by post-treatment residual EBV DNA. ${ }^{62,63}$ It should be noted, however, that the benefit of more intensive therapy may be limited by the late toxicities of high cumulative doses of chemotherapy, most notably cisplatin, which are not reported in some of the studies. ${ }^{60,64}$

Platinum-containing doublet regimens remain the first-line systemic treatment for recurrent or metastatic NPC. Cisplatin and fluorouracil have been the conventional choices. ${ }^{10}$ A recent study by Zhang et $\mathrm{al}^{65}$ demonstrated that the combination of cisplatin plus gemcitabine was superior to the combination of cisplatin and fluorouracil, in terms of median PFS (7.0 vs 5.6 months; hazard ratio $=0.55$; 95\% confidence interval, 0.44-0.68), although the cisplatin-gemcitabine group experienced more haematological toxicity, such as grade- 3 or higher leukopenia, neutropenia, and thrombocytopenia. ${ }^{65}$ This randomised controlled trial has thus established the role of cisplatin and gemcitabine combination as the chemotherapy of choice in recurrent or metastatic NPC.

\section{Surgery and targeted therapy}

As mentioned above, surgery is usually not considered in the routine management of NPC; yet salvage therapy can be considered an option for selected patients with local recurrence in the neck. ${ }^{66}$ Molecular targeted therapy is considered hopeful 
for many other types of carcinoma, but its efficacy in treating NPC has been disappointing; studies of inhibitors of epidermal growth factor receptor (eg cetuximab) and vascular endothelial growth factor (eg sunitinib) failed to show superiority over standard treatments, and were largely limited to phase II trials. ${ }^{8}$ Lee et $\mathrm{al}^{8}$ attributed its failure to the scarcity of authentic NPC models that can be utilised in the preclinical studies of new drugs, and increased incidence of drug-related toxicities such as bleeding. The development of immunotherapy is therefore exciting as it presents a new hope for managing NPC.

\section{Immunotherapy}

The presence of EBV and the expression of viral antigens in almost all NPC cases make this disease an attractive target for the development of immunotherapy. For example, EBV nuclear antigen I (EBNA1) and latent membrane protein 2 (LMP2) are frequently expressed in EBV-associated NPC, and a recombinant virus-based vaccine that encodes an inactive fusion protein containing fragments of EBNA1 and LMP2 was shown to be effective in inducing T-cell response in a local phase I trial. ${ }^{67}$ The vaccine is currently being tested in a phase II clinical trial (NCT01094405).

As EBV that persists as a latent infection is controlled by cytotoxic $\mathrm{T}$ lymphocytes $(\mathrm{CTL}){ }^{68}$ it follows that the use of EBV-specific CTL for NPC appears logical as a treatment strategy. Adoptive immunotherapy that includes infusion of autologous CTL has been tested in a number of clinical trials, and the results have been promising. For example, a study in Singapore showed that chemotherapy followed by EBV-specific CTL achieved a response rate (full or partial) of $71.4 \%$ in 38 patients, ${ }^{69}$ and a phase III trial is currently underway to assess its efficacy (NCT02578641).

Among all the immunotherapies available, checkpoint inhibitors seem to be the most rapidly developing. Programmed death ligand-1 (PD-L1) was found to be expressed on antigen-presenting cells, and its interaction with the programmed death-1 (PD-1) receptor on $\mathrm{T}$ cells inhibits downstream signalling of T cell receptors. ${ }^{70}$ Tumourassociated PD-L1 was also found to mediate immune suppression by various other mechanisms, such as facilitating $\mathrm{T}$ cell apoptosis and inducing regulatory T cells. ${ }^{71}$ With PD-L1 expressed in many different carcinomas, ${ }^{72}$ blockade of PD-L1 and/or the PD-1 receptor has become the focus of new cancer drug development in the past 5 years.

While PD-L1 inhibitor has recently gained much attention in the treatment of non-smallcell lung cancer, ${ }^{73}$ its progress in the treatment of advanced NPC is exciting and much awaited. Pembrolizumab was shown to be well-tolerated with significant anti-tumour activity in NPC in a phase Ib trial, ${ }^{74}$ and is currently in a phase II trial to confirm the response rate and efficacy in terms of improvement in OS (NCT02611960). Nivolumab has just completed phase II trials; the preliminary results showed that it is active in heavily pre-treated recurrent or metastatic patients, ${ }^{75,76}$ and that PD-L1 expression may predict benefits from nivolumab. ${ }^{75}$

\section{Conclusion}

Once a nightmare in the eyes of many Hong Kong inhabitants, NPC has become less prevalent in southern China, but it still poses a threat to Hong Kong citizens as it was ranked as the 10th most common cancer in the city. ${ }^{3}$ With clearer understanding of its pathophysiology and advances in technology, it is expected that more refined treatment strategies and novel therapeutic agents will be available in the near future.

\section{Acknowledgement}

I would like to thank Prof Brigette Ma from Department of Clinical Oncology, The Chinese University of Hong Kong for her comments and advice.

\section{References}

1. Gibb AG, van Hasselt CA, editors. Nasopharyngeal carcinoma. 2nd ed. Hong Kong: The Chinese University Press; 1999.

2. Nasopharyngeal cancer. Available from: http://www.chp. gov.hk/en/content/9/25/54.html. Accessed 12 Apr 2017.

3. Hong Kong Cancer Registry, Hospital Authority. Available from: www3.ha.org.hk/cancereg/statistics.html. Accessed 12 Apr 2017.

4. 2014 Review of cancer medicines on the WHO list of essential medicines: Nasopharyngeal carcinoma. Geneva: World Health Organization; 2014.

5. Ferlay J, Soerjomataram I, Ervik M, et al. GLOBOCAN 2012: Estimated cancer incidence, mortality and prevalence worldwide in 2012 v1.0. Lyon, France: International Agency for Research on Cancer; 2013.

6. Tang LL, Chen WQ, Xue WQ, et al. Global trends in incidence and mortality of nasopharyngeal carcinoma. Cancer Lett 2016;374:22-30.

7. Chan AT, Grégoire V, Lefebvre JL, et al. Nasopharyngeal cancer: EHNS-ESMO-ESTRO clinical practice guidelines for diagnosis, treatment and follow-up. Ann Oncol 2012;23 Suppl 7:vii83-5.

8. Lee AW, Ma BB, Ng WT, Chan AT. Management of nasopharyngeal carcinoma: current practice and future perspective. J Clin Oncol 2015;33:3356-64.

9. Pathology and genetics of head and neck tumours. In: Barnes L, Eveson JW, Reichart P, Sidransky D, editors. World Health Organization classification of tumours. Lyon: IARC Press; 2005.

10. Chua ML, Wee JT, Hui EP, Chan AT. Nasopharyngeal carcinoma. Lancet 2016;387:1012-24.

11. Lydiatt WM, Patel SG, O’Sullivan B, et al. Head and neck cancers-major changes in the American Joint Committee 
on Cancer eighth edition cancer staging manual. CA Cancer J Clin 2017;67:122-37.

12. Raghupathy R, Hui EP, Chan AT. Epstein-Barr virus as a paradigm in nasopharyngeal cancer: from lab to clinic. Am Soc Clin Oncol Educ Book 2014: 149-53.

13. de Martel C, Ferlay J, Franceschi S, et al. Global burden of cancers attributable to infections in 2008: a review and synthetic analysis. Lancet Oncol 2012;13:607-15.

14. Raab-Traub N. Epstein-Barr virus in the pathogenesis of NPC. Semin Cancer Biol 2002;12:431-41.

15. Wu CC, Fang CY, Hsu HY, et al. EBV reactivation as a target of luteolin to repress NPC tumorigenesis. Oncotarget 2016;7:18999-9017.

16. Xu FH, Xiong D, Xu YF, et al. An epidemiological and molecular study of the relationship between smoking, risk of nasopharyngeal carcinoma, and Epstein-Barr virus activation. J Natl Cancer Inst 2012;104:1396-410.

17. Hsu WL, Chen JY, Chien YC, et al. Independent effect of EBV and cigarette smoking on nasopharyngeal carcinoma: a 20-year follow-up study on 9,622 males without family history in Taiwan. Cancer Epidemiol Biomarkers Prev 2009;18:1218-26.

18. Lo EJ, Bell D, Woo JS, et al. Human papillomavirus and WHO type I nasopharyngeal carcinoma. Laryngoscope 2010;120:1990-7.

19. Stenmark MH, McHugh JB, Schipper M, et al. Nonendemic HPV-positive nasopharyngeal carcinoma: association with poor prognosis. Int J Radiat Oncol Biol Phys 2014;88:5808.

20. Lin DC, Meng X, Hazawa M, et al. The genomic landscape of nasopharyngeal carcinoma. Nat Genet 2014;46:866-71.

21. Dai W, Zheng H, Cheung AK, Lung ML. Genetic and epigenetic landscape of nasopharyngeal carcinoma. Chin Clin Oncol 2016;5:16.

22. Li YY, Chung GT, Lui VW, et al. Exome and genome sequencing of nasopharynx cancer identifies NF-kB pathway activating mutations. Nat Commun 2017;8:14121.

23. Ho JH. Nasopharyngeal carcinoma (NPC). Adv Cancer Res 1972;15:57-92.

24. Yu MC, Ho JH, Lai SH, Henderson BE. Cantonese-style salted fish as a cause of nasopharyngeal carcinoma: report of a case-control study in Hong Kong. Cancer Res 1986;46:956-61.

25. Guo X, Johnson RC, Deng H, et al. Evaluation of nonviral risk factors for nasopharyngeal carcinoma in a high-risk population of Southern China. Int J Cancer 2009;124:29427.

26. Fung SY, Lam JW, Chan KC. Clinical utility of circulating Epstein-Barr virus DNA analysis for the management of nasopharyngeal carcinoma. Chin Clin Oncol 2016;5:18.

27. Chan KC, Hung EC, Woo JK, et al. Early detection of nasopharyngeal carcinoma by plasma Epstein-Barr virus DNA analysis in a surveillance program. Cancer 2013;119:1838-44.

28. Chan KC, Woo JK, King A, et al. Analysis of Plasma Epstein-Barr Virus DNA to Screen for Nasopharyngeal Cancer. N Engl J Med 2017;377:513-22.

29. Chan AT, Lo YM, Zee B, et al. Plasma Epstein-Barr virus DNA and residual disease after radiotherapy for undifferentiated nasopharyngeal carcinoma. J Natl Cancer Inst 2002;94:1614-9.

30. Lin JC, Wang WY, Chen KY, et al. Quantification of plasma Epstein-Barr virus DNA in patients with advanced nasopharyngeal carcinoma. N Engl J Med 2004;350:2461-
70.

31. Le QT, Jones CD, Yau TK, et al. A comparison study of different PCR assays in measuring circulating plasma Epstein-Barr virus DNA levels in patients with nasopharyngeal carcinoma. Clin Cancer Res 2005;11:57007.

32. Lin JC, Wang WY, Liang WM, et al. Long-term prognostic effects of plasma Epstein-Barr virus DNA by minor groove binder-probe real-time quantitative $\mathrm{PCR}$ on nasopharyngeal carcinoma patients receiving concurrent chemoradiotherapy. Int $\mathrm{J}$ Radiat Oncol Biol Phys 2007;68:1342-8.

33. An X, Wang FH, Ding PR, et al. Plasma Epstein-Barr virus DNA level strongly predicts survival in metastatic/ recurrent nasopharyngeal carcinoma treated with palliative chemotherapy. Cancer 2011;117:3750-7.

34. Hou X, Zhao C, Guo Y, et al. Different clinical significance of pre- and post-treatment plasma Epstein-Barr virus DNA load in nasopharyngeal carcinoma treated with radiotherapy. Clin Oncol (R Coll Radiol) 2011;23:128-33.

35. Ferrari D, Codecà C, Bertuzzi $C$, et al. Role of plasma EBV DNA levels in predicting recurrence of nasopharyngeal carcinoma in a western population. BMC Cancer 2012;12:208.

36. Zhao FP, Liu X, Chen XM, et al. Levels of plasma EpsteinBarr virus DNA prior and subsequent to treatment predicts the prognosis of nasopharyngeal carcinoma. Oncol Lett 2015;10:2888-94.

37. Lee VH, Kwong DL, Leung TW, et al. Prognostication of serial post-intensity-modulated radiation therapy undetectable plasma EBV DNA for nasopharyngeal carcinoma. Oncotarget 2017;8:5292-308.

38. Leung SF, Chan KC, Ma BB, et al. Plasma Epstein-Barr viral DNA load at midpoint of radiotherapy course predicts outcome in advanced-stage nasopharyngeal carcinoma. Ann Oncol 2014;25:1204-8.

39. To EW, Chan KC, Leung SF, et al. Rapid clearance of plasma Epstein-Barr virus DNA after surgical treatment of nasopharyngeal carcinoma. Clin Cancer Res 2003;9:3254-9.

40. Hsu CL, Chang KP, Lin CY, et al. Plasma Epstein-Barr virus DNA concentration and clearance rate as novel prognostic factors for metastatic nasopharyngeal carcinoma. Head Neck 2012;34:1064-70.

41. Wang WY, Twu CW, Chen HH, et al. Plasma EBV DNA clearance rate as a novel prognostic marker for metastatic/ recurrent nasopharyngeal carcinoma. Clin Cancer Res 2010;16:1016-24.

42. Peng G, Wang T, Yang KY, et al. A prospective, randomized study comparing outcomes and toxicities of intensitymodulated radiotherapy vs. conventional two-dimensional radiotherapy for the treatment of nasopharyngeal carcinoma. Radiother Oncol 2012;104:286-93.

43. Kam MK, Leung SF, Zee B, et al. Prospective randomized study of intensity-modulated radiotherapy on salivary gland function in early-stage nasopharyngeal carcinoma patients. J Clin Oncol 2007;25:4873-9.

44. Pow EH, Kwong DL, McMillan AS, et al. Xerostomia and quality of life after intensity-modulated radiotherapy vs. conventional radiotherapy for early-stage nasopharyngeal carcinoma: initial report on a randomized controlled clinical trial. Int J Radiat Oncol Biol Phys 2006;66:981-91.

45. Lee AW, Foo W, Law SC, et al. Reirradiation for recurrent nasopharyngeal carcinoma: factors affecting the therapeutic ratio and ways for improvement. Int J Radiat 
Oncol Biol Phys 1997;38:43-52.

46. Teo PM, Kwan WH, Chan AT, Lee WY, King WW, Mok $\mathrm{CO}$. How successful is high-dose ( $>$ or $=60 \mathrm{~Gy}$ ) reirradiation using mainly external beams in salvaging local failures of nasopharyngeal carcinoma? Int J Radiat Oncol Biol Phys 1998;40:897-913.

47. Chen C, Fee W, Chen J, et al. Salvage treatment for locally recurrent nasopharyngeal carcinoma (NPC). Am J Clin Oncol 2014;37:327-31.

48. Lu TX, Mai WY, Teh BS, et al. Initial experience using intensity-modulated radiotherapy for recurrent nasopharyngeal carcinoma. Int J Radiat Oncol Biol Phys 2004;58:682-7.

49. Chua DT, Sham JS, Leung LH, Au GK. Re-irradiation of nasopharyngeal carcinoma with intensity-modulated radiotherapy. Radiother Oncol 2005;77:290-4.

50. Qiu S, Lin S, Tham IW, Pan J, Lu J, Lu JJ. Intensitymodulated radiation therapy in the salvage of locally recurrent nasopharyngeal carcinoma. Int J Radiat Oncol Biol Phys 2012;83:676-83.

51. Hua YJ, Han F, Lu LX, et al. Long-term treatment outcome of recurrent nasopharyngeal carcinoma treated with salvage intensity modulated radiotherapy. Eur J Cancer 2012;48:3422-8.

52. Han F, Zhao C, Huang SM, et al. Long-term outcomes and prognostic factors of re-irradiation for locally recurrent nasopharyngeal carcinoma using intensity-modulated radiotherapy. Clin Oncol (R Coll Radiol) 2012;24:569-76.

53. Qiu S, Lu J, Zheng W, et al. Advantages of intensity modulated radiotherapy in recurrent T1-2 nasopharyngeal carcinoma: a retrospective study. BMC Cancer 2014;14:797.

54. Xiao W, Liu S, Tian Y, et al. Prognostic significance of tumor volume in locally recurrent nasopharyngeal carcinoma treated with salvage intensity-modulated radiotherapy. PLoS One 2015;10:e0125351.

55. Tian YM, Guan Y, Xiao WW, et al. Long-term survival and late complications in intensity-modulated radiotherapy of locally recurrent T1 to T2 nasopharyngeal carcinoma. Head Neck 2016;38:225-31.

56. Kong L, Wang L, Shen C, Hu C, Wang L, Lu JJ. Salvage intensity-modulated radiation therapy (IMRT) for locally recurrent nasopharyngeal cancer after definitive IMRT: a novel scenario of the modern era. Sci Rep 2016;6:32883.

57. Kong L, Hu J, Guan X, Gao J, Lu R, Lu JJ. Phase I/II trial evaluating carbon ion radiotherapy for salvaging treatment of locally recurrent nasopharyngeal carcinoma. J Cancer 2016;7:774-83.

58. Blanchard P, Lee A, Marguet S, et al. Chemotherapy and radiotherapy in nasopharyngeal carcinoma: an update of the MAC-NPC meta-analysis. Lancet Oncol 2015;16:64555.

59. Sun Y, Li WF, Chen NY, et al. Induction chemotherapy plus concurrent chemoradiotherapy versus concurrent chemoradiotherapy alone in locoregionally advanced nasopharyngeal carcinoma: a phase 3, multicentre, randomised controlled trial. Lancet Oncol 2016;17:150920.

60. Cao SM, Yang Q, Guo L, et al. Neoadjuvant chemotherapy followed by concurrent chemoradiotherapy versus concurrent chemoradiotherapy alone in locoregionally advanced nasopharyngeal carcinoma: a phase III multicentre randomised controlled trial. Eur J Cancer 2017;75:14-23.
61. Chen L, Hu CS, Chen XZ, et al. Adjuvant chemotherapy in patients with locoregionally advanced nasopharyngeal carcinoma: Long-term results of a phase 3 multicentre randomised controlled trial. Eur J Cancer 2017;75:150-8.

62. Chan AT, Ngan RK, Hui EP, et al. A multicenter randomized controlled trial of adjuvant chemotherapy in nasopharyngeal carcinoma with residual plasma EBV DNA following primary radiotherapy or chemoradiotherapy. J Clin Oncol 2012;30(Suppl):abstract 5511.

63. Hui EP, Ma BB, Chan KC, et al. Clinical utility of plasma Epstein-Barr virus DNA and ERCC1 single nucleotide polymorphism in nasopharyngeal carcinoma. Cancer 2015;121:2720-9.

64. Lee AW, Tung SY, Chua DT, et al. Randomized trial of radiotherapy plus concurrent-adjuvant chemotherapy vs radiotherapy alone for regionally advanced nasopharyngeal carcinoma. J Natl Cancer Inst 2010;102:1188-98.

65. Zhang L, Huang Y, Hong S, et al. Gemcitabine plus cisplatin versus fluorouracil plus cisplatin in recurrent or metastatic nasopharyngeal carcinoma: a multicentre, randomised, open-label, phase 3 trial. Lancet 2016;388:1883-92.

66. Chan JY. Surgical salvage of recurrent nasopharyngeal carcinoma. Curr Oncol Rep 2015;17:433.

67. Hui EP, Taylor GS, Jia H, et al. Phase I trial of recombinant modified vaccinia ankara encoding Epstein-Barr viral tumor antigens in nasopharyngeal carcinoma patients. Cancer Res 2013;73:1676-88.

68. Khanna R, Burrows SR. Role of cytotoxic T lymphocytes in Epstein-Barr virus-associated diseases. Annu Rev Microbiol 2000;54:19-48.

69. Chia WK, Teo M, Wang WW, et al. Adoptive T-cell transfer and chemotherapy in the first-line treatment of metastatic and/or locally recurrent nasopharyngeal carcinoma. Mol Ther 2014;22:132-9.

70. Khalil DN, Smith EL, Brentjens RJ, Wolchok JD. The future of cancer treatment: immunomodulation, CARs and combination immunotherapy. Nat Rev Clin Oncol 2016;13:273-90.

71. Chen L, Han X. Anti-PD-1/PD-L1 therapy of human cancer: past, present, and future. J Clin Invest 2015;125:3384-91.

72. Chen DS, Mellman I. Oncology meets immunology: the cancer-immunity cycle. Immunity 2013;39:1-10.

73. Reck M, Rodríguez-Abreu D, Robinson A, et al. Pembrolizumab versus chemotherapy for PD-L1-positive non-small-cell lung cancer. N Engl J Med 2016;375:1823-33.

74. Hsu C, Lee SH, Ejadi S, et al. Antitumor activity and safety of pembrolizumab in patients with PD-L1-positive nasopharyngeal carcinoma: Interim results from a phase 1b study. Eur J Cancer 2015;51 Suppl 3:S558.

75. Ma BB, Goh BC, Lim WT, et al. Multicenter phase II study of nivolumab in previously treated patients with recurrent and metastatic non-keratinizing nasopharyngeal carcinoma [abstract]. Proceedings of the 107th Annual Meeting of the American Association for Cancer Research; 2017 Apr 1-5; Washington, DC: Philadelphia; 2017. Available from: http://www.abstractsonline.com/ pp8/\#!/4292/presentation/12342. Accessed Aug 2017.

76. Delord JP, Hollebecque A, De Boer JP, et al. An open-label, multicohort, phase I/II study to evaluate nivolumab in patients with virus-associated tumors (CheckMate 358): Efficacy and safety in recurrent or metastatic nasopharyngeal carcinoma. J Clin Oncol 2017;35(Suppl):abstract 6025. 